\title{
Perspectivas futuras del Instituto de Medicina Tropical Alexander von Humboldt *
}

Future Perspectives of the Institute of Tropical Medicine Alexander von Humboldt *

Theresa J. OChOA WoOdell ${ }^{1}$

$\mathfrak{E}$ n primer lugar quiero agradecer la invitación del Dr. Eduardo Gotuzzo y del Dr. Alejandro Llanos para dirigir unas palabras en esta ceremonia de aniversario en nombre de las nuevas generaciones del instituto. En estos 50 años de creación institucional celebramos con mucha alegría y entusiasmo los logros alcanzados por nuestro Instituto y miramos con optimismo el futuro.

Como hemos escuchado en las presentaciones del Dr. Humberto Guerra quien ha narrado la historia de colaboración y cooperación internacional y del Dr. Gotuzzo quien ha hecho un recuento de nuestros logros; en estos 50 años nos hemos consolidado como un instituto cuya misión es generar y difundir conocimiento, ciencia y tecnología que contribuyan a prevenir, diagnosticar, tratar y controlar las enfermedades infecciosas y tropicales, promoviendo y ejerciendo liderazgo y excelencia en investigación, formación integral y servicios, para mejorar la calidad de vida de las personas, la sociedad y su entorno.

Antes de hablar del futuro, necesitamos primero reconocer y agradecer la labor realizada por nuestros profesores, maestros y mentores, Drs. Raúl León Barúa, Humberto Guerra, Eduardo Gotuzzo, Alejandro Llanos, Ciro Maguiña, Angélica Terashima, Juan Echevarria, Frine Samalvides, Beatriz Bustamante, Carlos Seas, Pedro Legua, Jorge Arévalo, Francisco Bravo y tantos otros, que no solo han logrado que Tropicales sea un referente de docencia e investigación en el Perú, en Latinoamérica y porque no decir en el mundo; si no que también han apoyado a las nuevas generaciones en nuestro desarrollo personal, profesional y como investigadores. A todos ellos nuestra gratitud.

Hoy que celebramos este hito tan importante, el 50 Aniversario, es momento de reflexionar un poco sobre las perspectivas futuras de nuestra Institución ¿Hacia dónde vamos? ¿Qué queremos alcanzar? ¿Cuáles son nuestros principales retos? ¿Qué debemos hacer para alcanzar nuestras metas? ¿Cómo logramos el crecimiento de nuestra institución?

No son preguntas fáciles; requieren de una reflexión profunda y por supuesto de un planeamiento estratégico. Sin embargo, en esta

Profesora asociada. Facultad de Medicina. Investigadora principal del Instituto de Medicina Tropical Alexander von Humboldt, UPCH.

* Leído el 23 de marzo, en las celebraciones por el 50 aniversario del IMTAVH. 
celebración quisiera dar una mirada rápida a algunos de estos retos.

¿Qué buscamos alcanzar en el futuro? Buscamos alcanzar nuestra visión: ser un Instituto multidisciplinario especializado en enfermedades infecciosas y tropicales, con liderazgo y presencia global; que crece, investiga, innova y se diversifica; que propone y promueve políticas públicas y transferencia tecnológica, contribuyendo al desarrollo del país.

¿Cómo logramos alcanzar esta meta? Son muchos los retos y tareas. Quiero compartir con ustedes algunos de nuestras ideas del plan estratégico y la opinión de algunos de mis colegas y amigos investigadores jóvenes del instituto, a quien les hice la mima pregunta.

En primer lugar debemos lograr la sostenibilidad y el desarrollo institucional. Como ustedes saben, la sostenibilidad es difícil para universidades e instituciones privadas sin fines de lucro, que no reciben apoyo económico directo por parte del gobierno. Por lo tanto, la forma de lograr la sostenibilidad es a través del financiamiento de proyectos de investigación. Debemos escribir proyectos institucionales grandes, con la participación de todos los grupos; trabajar en equipo. Esta investigación debe continuar con los más altos estándares metodológicos y éticos; debemos mantener por sobre todo la integridad científica. Por otro lado, podemos hacer más consultorías, aprovechando la experiencia clínica y de investigación que tenemos; así como ofrecer más servicios de apoyo diagnóstico a la comunidad. Como ustedes han escuchado a lo largo del día, varios de los grupos de investigación han desarrollado nuevos métodos diagnósticos, sobretodo métodos moleculares, que debemos ahora poner al servicio de los pacientes.
En segundo lugar debemos lograr la consolidación del talento humano. Esto es muy importante $y$ es uno de nuestros principales desafíos. Tenemos un gran grupo de investigadores entrenados fuera, con maestría, doctorado, proyectos financiados y colaboraciones internacionales, pero que no son incorporados a la universidad como docenes, para empezar una carrera académica como investigadores. Aquí mi pedido a los Decanos y Vice-Decanos para que incorporen a estos investigadores en la plana docente de sus Facultades. Debemos impulsar políticas para la atracción y retención del talento, pero sostenibles en el tiempo. Debemos trabajar con el Vice-Rectorado Académico y la Escuela de Post-grado para impulsar la formación de los MD-PhD. Los alumnos interesado en investigación debería poder terminar la carrera de medicina y en un par de años más el doctorado. Nuestra experiencia con los "physician scientist" o médicos-científicos, es espectacular, pero esporádica.

Debemos lograr el crecimiento de la oferta académica. Tenemos el reconocido Curso Gorgas de Medicina Clínica Tropical, la pasantía internacional para médicos residentes de Latinoamérica, el curso de medicina tropical para los alumnos de medicina, el curso de PCR de la Unidad de Epidemiologia Molecular, entre otros. Sin embargo, podemos ofrecer más cursos, diplomados y maestrías, basados en nuestra amplia experiencia clínica, de docencia, investigación y colaboración internacional.

Debemos lograr mayor impacto de la investigación en el desarrollo del país. Mirando al futuro, este es nuestro mayor reto. La primera tarea es darle mayor visibilidad a nuestra investigación. Debemos transcribir nuestras publicaciones a un lenguaje sencillo y resumido, para socializar nuestros resultados 
con la comunidad y los decisores del gobierno y del Ministerio de Salud. Debemos socializar la ciencia; para esto necesitamos trabajar con comunicadores, sociólogos y educadores. Nuestra investigación debe traducirse en políticas de salud pública y transferencia tecnológica, contribuyendo así a mejorar la calidad de vida de las personas, la sociedad y su entorno.

Todo esto solo lo podremos alcanzar si logramos mayor eficiencia de la gestión institucional. Necesitamos "institucionalizar" nuestro instituto. Debemos mejorar la gobernanza; optimizar nuestros espacios y recursos; promover el trabajo compartido en laboratorios "core", como ocurre por ejemplo en la Unidad de Epidemiologia Molecular que alberga a varios grupos de investigación como malaria, leishmania, tuberculosis, HTLV1, entéricas. Debemos mantener y afianzar nuestras alianzas estratégicas con otras instituciones, así como promover y facilitar la colaboración científica nacional e internacional. Un aspecto clave aquí es el vínculo y triangulación entre el Hospital, el Instituto y la Facultad de Medicina; debemos fortalecer esta relación.
En resumen, miramos al futuro como un gran reto, pero con mucho optimismo y responsabilidad. Estamos optimistas porque tenemos un grupo grande de "jóvenes" investigadores y profesionales bien entrenados, muy capaces, pero sobretodo muy comprometidos con nuestra institución. Tenemos una nueva generación de expertos en malaria, tuberculosis, leishmaniasis, inmunología, medicina tropical, resistencia antibiótica, infectología clínica, control de infecciones intra-hospitalarias, epidemiología, biología molecular, VIH, HTLV-I, parásitos intestinales, micología, amebas de vida libre, entre otros.

El Instituto Medicina Tropical Alexander von Humboldt reúne a médicos, biólogos, microbiólogos, tecnólogos, enfermeras, epidemiólogos, salubristas, administradores y otros profesionales de la salud. Todos nosotros celebramos con entusiasmo este 50 aniversario y nos compromete a continuar con el crecimiento y desarrollo del Instituto. 